\title{
FORM: AN APOLLONIAN MODERNITY
}

\section{MICHAEL C. BEHRENT}

History Department, Appalachian State University

E-mail: behrentmc@appstate.edu

Life is at once flux without pause and yet something enclosed in bearers and contents, formed about midpoints, individualized, and therefore always a bounded form which continually jumps its bounds.

Georg Simmel, "The Transcendent Character of Life"

You tell me to violate the boundaries of others, I warn you to return within your own.

Petrarch, Invective Contra Medicum ${ }^{2}$

History, Georg Simmel tells us, consist of a conflict between life and form. Life-the physical and biological basis of existence-is, in itself, bereft of culture and devoid of form. Through culture, however, the energies life harbors can become manifest. "We speak of culture," Simmel writes, "whenever life produces certain forms in which it expresses and realizes itself; works of art, religions, sciences, technologies, laws, and innumerable others." ${ }^{3}$ Life, in this way, produces something related to yet different from itself: "Life as such is formless, yet incessantly generates forms for itself." 4 Though form proceeds from life, conflict between them is unavoidable. Form struggles to liberate itself from the "pulse of life," while life attempts to draw form back into its own "immediacy," in a gambit to reduce culture's achievements to "direct manifestations of life." The unprecedented character of modern culture, Simmel maintained, lies in the fact that life's forces were henceforth targeting the very "principle of form." In the latest and most radical round of this conflict, life's cultural partisans assert that

Georg Simmel, “The Transcendent Character of Life” (1918), in Simmel, On Individuality and Social Forms, ed. and trans. Donald N. Levine (Chicago, 1971), 353-74, at 363.

2 Petrarch, Invective Contra Medicum, ed. P. G. Ricci (Rome, 1950), quoted in RP, 40.

3 Simmel, "The Conflict in Modern Culture" (1918), in Simmel, On Individuality and Social Forms, 375-93, at 375.

4 Ibid., 376.

$5 \quad$ Ibid., 377, original emphasis. 
they no longer need the opaque and alien resources of form to express life's energies; form can be jettisoned, mediation dispensed with, and life can exist and relish its powers in their most unalloyed purity.

In Simmel's account of the struggle between life and form, the philosophical bassline of Seigel's oeuvre can be unmistakably heard. True, the residual idealism and Lebensphilosophie lining Simmel's though is largely absent from Seigel's, which is too empirical and historical in orientation to indulge the notion that something called form might "express" something called life. Yet cast in a more pragmatic vein, Seigel shares most of Simmel's insights. The notion that culture is rooted in what he, throughout his career, has called "ordinary" or "everyday" human "life" is a leitmotif of his work. Another recurring theme in his books is the way that various tendencies in modern culture open a yawning breach between ordinary life and cultural forms. Marx's Fate considers the disquieting intellectual consequences of viewing the world as a deceptive illusion. In his writings on the avant-garde, Seigel explores how the belief that art provides access to a radical form of freedom that is completely emancipated from ordinary human constraints leads to a peculiarly modern kind of askesis that devalues everyday life and its concerns. And in The Idea of the Self, he examines how the heady prospect of making the mind's capacity for reflection coextensive with human existence as such results in the negation of the "concrete self," which is fated to grapple with practical matters such as bodily needs and the existence of other people.

At the same time, Seigel has continuously demonstrated how cultural expression is the means through which the tensions and conflicts that characterize human existence take on a shape, acquiring a significance that, confined to themselves, would remain implicit at best. The various ways in which Petrarch and his fellow humanists combined, in their work, the competing ideals of eloquence and wisdom; the lifelong conflict in Marx's life and thought between philosophical abstraction and empirical realism (which he undertook to resolve in Capital with such self-defeating boldness that the work remained tragically unfinished); the tension between the vaporization and centralization of self in Baudelaire, which he expressed in poetry that articulated disturbingly modern themes in taut classical form; Duchamp's quest for a freedom so complete that it undertook a kind of systematic renaming of the world, transforming the shared meaning of things into an intensely personal but hermetic vocabulary, which he paradoxically offered to the public through paintings, readymades, and, ultimately, the playing of chess: through each of these examples, Seigel shows how culture is the means through which the storms and stresses of life become, through form, something distinct from life as such. And this is the final way in which Seigel's thought resembles Simmel's: both believe that life and form are destined to clash, but that form can only survive by preserving its autonomy in relation to life. The inclination, which they say is so pervasive in modern culture, 
to absorb form into life can only result in the dissolution of culture-and the concomitant loss of any external perspective from which life can be surveyed and assessed. Though adumbrated in Marx's Fate, this idea becomes the major theme of Bohemian Paris and The Private Worlds of Marcel Duchamp, in which Seigel addresses the powerful temptation to dissolve form into life that he finds in avantgarde art. This is also the reason why the notion of "boundaries," understood as borders between form and life that preserves form's autonomy and integrity (or other culturally important distinctions) is yet another recurring motif in Seigel's oeuvre. "[L]ife," writes Simmel, "is always in latent opposition to form." Form, Seigel teaches us, in turn, is always in latent opposition to life.

My point in comparing Simmel and Seigel is not primarily to show that the former influenced the latter, even if this is undeniably true to some degree. It is, rather, that Seigel's work belongs to the same tradition of historically informed social thought, in addition to sharing many of Simmel's concerns: the character of modern social relations, the nature of modern individuality, and the ways in which the latter have shaped distinctly modern practices of cultural expression. These preoccupations lead Seigel, like Simmel before him, to give special attention to the problem of form. As I argue in this forum's introduction, Seigel's interest in form always arises from the way it emerges as an alternative to the countervailing psychological, cultural, and social forces of modernity. Seigel, I explain, repeatedly uses imagery evoking fluidity and dissolution when describing modernity's distinctive traits: the "repeated slipping in and out of personal integration" $(M F, 37) ;^{7}$ "self-diffusion" and "personal decomposition" $(B P, 268,114)$; the substitution of "fluidity for fixity, chance and accident for taste and habit" $(P W, 13)$; and "fluidity, energy, and the promise of transformation" $(M B L, 482)$. Form, as Seigel understands it, exists in a dialectical relationship with these forces of dissolution, which embody what Simmel saw as modern culture's tendency to revert to life's "formlessness." Though he never explicitly defines or thematizes the concept, "form" and related terms gain explanatory traction in his work in relation to three themes: the coherence of individual biographies, art's autonomy vis-à-vis life, and a conception of modernity emphasizing the possibility of formal unity rather than the risk of amorphous flux.

\section{FORM AS THE SHAPE OF A LIFE}

To begin with, the idea of form lies at the heart of Seigel's approach to intellectual history, and specifically his conception of biography. Individual lives can be significant objects of historical study because, he contends, they have a

Ibid., 377 .

7 Seigel is quoting Donald Schon, Invention and the Evolution of Ideas (London, 1969). 
"shape," a form, which the historian can reconstruct. Seigel explicitly makes this point in his 1992 introduction to Marx's Fate (first published in 1978). Writing after the fall of the Berlin Wall, he notes that the "collapse of revolutionary expectations has fed those currents in modern culture that cheerfully turn their backs on meaning itself, sometimes even regarding the search for it as a tactic of oppression and identifying freedom with mere play and the undermining of stable personal identities and values." Against such postmodernist skepticism, Seigel affirms, "To say that Marx had a fate, that his life had a meaningful, even tragic shape, is to side against these currents, to assert that human lives can be meaningful wholes even if human history can never be made to constitute one" $(M F, \mathrm{x})$. Seigel makes the same point several years later in The Private Worlds of Marcel Duchamp. Some would have us believe that Duchamp "undermined the goal of seeking meaning through artistic activity" and "dissolved his own subjectivity as an artist," preferring to float "through life freely and without direction, taking each moment as it came and bobbling along on a sea of accident and chance." Challenging this view, Seigel maintains, as he had with Marx, that Duchamp's career forms "a coherent whole" $(P W, 12)$.

Yet how does Seigel justify his assertion that not only philosophical works and artistic expression, but also the lives that produce them, constitute "wholes" endowed with definite form? His intuition is that individuals often provide us with the clues through which we should interpret them. The scholar must seek out "symbols and patterns" hinted at by an author or those close to him $(M F, 7)$, the "identifiable and interrelated ideas and impulses" (even if they are a "small number") that are often connected to a set of "personal themes" that recur over the course of an individual's life $(P W, 12)$. Seigel is specifically concerned with identifying themes that are present both in an artist or an intellectual's work and in the records of their private or personal lives. Seigel assumes that the ideas to which such individuals will return throughout their careers are typically those with which they must also grapple in their everyday lives. In his extraordinary chapter on the Marx household during the London years, Seigel examines the conflicted way in which Marx undertook to pursue his intellectual work while struggling to support a family for which he cared deeply. Seigel concludes, "[h] owever much his outside involvements conflicted with it, Marx was drawn ever back into his family, to counter the feeling of weakness that the attempt to comprehend and transform society bred." This alternation between "the idealization and rejection of the actual world" that shaped Marx's attitude to his home life resurfaced, Seigel argues, in the dialectic "between commitment and withdrawal" that characterized Marx's political activities ( $M F, 289)$. More boldly still, Seigel sees the same dynamic at work in Marx's attempts to decipher modern economics, notably in the tension between his efforts to identify a single theoretical principle (the declining rate of profit) that could explain capitalism's seemingly chaotic nature 
and his fear that economic relations were hopelessly irrational. In a similar vein, Seigel examines the recurrence of Duchamp's ambivalence towards desire-his insistence on "disillusionment as a consequence of sexual possession, and [his] celebration of desire without fulfillment" $(P W, 199)$-as a theme that unites both Duchamp's life and his art (however much he tried to cover the tracks leading back to his private lair of meaning). "Wholeness" and "coherence" are, for Seigel, something that happens to a life; at the very least, they are ends towards which individuals strive, however elusive they ultimately prove. Cultural expression is one way that individuals can give form to their preoccupations and contradictions. Form, in this sense, is less a given than a telos, a destiny, through which personal struggles finally acquire some of the resolution and clarity that cultural tools such as language and art are uniquely positioned to offer.

The reason lives can generate recurring symbolic patterns that provide clues to their interpretation in the first place is because the quest for personal identity and integration is, for Seigel, a fundamental tendency of human nature. The importance of Erik Erikson to Seigel's thinking (as Thomas Laqueur reminds us in his contribution) is, in this respect, crucial. For Erikson, human life consists of a series of stages, each of which encounters a distinctive crisis, through which individual identity becomes an increasingly well-defined whole. During childhood, Erikson believed, human beings acquire the "ego values" required to generate a "sense of ego identity," which he defines as "the accrued confidence that one's ability to maintain inner sameness and unity (one's ego in the psychological sense) is matched by the sameness and continuity of one's meaning for others." 8 This "inner sameness and unity" that, for Erikson, constitutes identity, is what Seigel has in mind when he speaks of the "wholeness," "coherence," and "shape" of a life. From this standpoint, what makes intellectuals and other cultural figures interesting is the way that they ask questions or engage in other pursuits that challenge this "inner sameness and continuity." In some instances, this may result in a specific conflict or contradiction that an individual wrestles with, becoming the very basis of his or her "inner sameness and continuity." Thus the conflict between "[p]hilosophical idealism and materialist realism" was the basic dilemma of "Marx's thought but also of his life"; but this "living contradiction" is precisely why Marx's life can be seen as consisting of a "single destiny" $(M F, 390)$. In a remarkable essay on Émile Durkheim, Seigel argues that a similar tension was the inner dynamic of the French sociologist's life and thought, specifically that between "individual self-affirmation and social obligation." Just as each new stage of Marx's development led him, in Seigel's account, to detect in his previous position a lingering residue of idealism, so "each of [Durkheim's] attempts to

Erik H. Erikson, "Growth and Crises of the Healthy Personality," in Erikson, Identity and the Life Cycle (New York, 1980; first published 1959), 51-170, at 94. 
reconstitute community through individuality revealed a weakness that allowed the dreaded power of egotism to break through.” For this reason, Durkheim felt compelled to "discover new forms of social integration, more able to restrain individual desiring." "Seigel explains the broader conclusion of these insights as follows: "Comparable contradictions, expressed in comparable patterns of recurrence, can be found in the careers of other thinkers. The attempt to discover such patterns, linking thought to the personal and social experience out of which it arises, is - I would argue - the purpose of psychologically oriented biographical studies in intellectual history." 10 Thus while many individuals aspire to give their lives form by achieving personal integration, Seigel's work on Marx and Durkheim (among others) shows that form's pattern may consist of a problem to which an individual is compulsively drawn or a contradiction that she or he strives single-mindedly to overcome.

\section{FORM AS ART'S AUTONOMY FROM LIFE}

Thus for Seigel, form refers, in the first place, to a characteristic of human lives as such: their potential for "wholeness" or "coherence." But form, in his thinking, also refers to something more specific: the attributes of cultural expression and cultural artifacts that are distinct from (as Simmel would put it) the "formless" flux of life itself. Throughout his career, Seigel has interested himself in the way that art articulates the dilemmas of everyday life while distinguishing itself from ordinary existence through formal properties that are less evident in life itself. This interest appears as early as Seigel's first book. In his analysis, rhetoric, for the Renaissance humanists, was both a lofty ideal and an activity grounded in and oriented towards everyday life. The humanists' fascination with Ciceronian eloquence provided them with a powerful incentive to free themselves from the constraints of contemporary literary genres. At the same time, rhetoric had an inherently social and communicative character, since its purpose was to sway an audience's opinion, a task that largely inoculated the humanists from the flights of abstraction and hair-splitting pedantry to which philosophy, in its scholastic form, was prone. The notion that it is precisely to the extent that cultural expression retains its most formal qualities, resisting the modern siren call that it dissolve into life itself, is a major concern of Seigel's. While this idea is central to the argument of Bohemian Paris and The Private Worlds of Marcel Duchamp (and is the subject of Thomas Ort's essay in this forum), it is also central to some of Seigel's shorter and more occasional writings. The fact that

$9 \quad$ Jerrold Seigel, “Autonomy and Personality in Durkheim," Journal of the History of Ideas 48/3 (1987), 483-507, at 505, 504.

$10 \quad$ Ibid., 505. 
it appears in these instances is indicative both of its importance to his broader outlook and of his concern that contemporary culture placed increasingly little stock in the autonomy of form.

In a book review from 1984, Seigel took issue with the trend in recent critical practice to see modern literature as incipiently political. In Madame Bovary on Trial, ${ }^{11}$ Dominick LaCapra, an intellectual historian who has been particularly receptive to contemporary critical theory, notably deconstruction, examined the 1857 trial in which Gustave Flaubert's masterpiece was accused of sapping society's moral foundation. Madame Bovary, LaCapra argues, was charged with this implicitly ideological crime because Flaubert had used his mastery of literary form to undermine and "carnivalize" a range of contemporary political, social, and moral values. In his review, Seigel expresses a prima facie skepticism towards LaCapra's thesis. After all, Seigel observes, Flaubert was acquitted. He also notes that for all of his sophisticated literary analysis, LaCapra fails to consider that the trial lawyers were themselves practicing rhetoric - a discreet allusion, perhaps, to the themes of Seigel's first book. LaCapra's primary goal, Seigel recognizes, is to show that Flaubert's literary technique, notably the style indirect libre, which leaves the boundaries between character voice and authorial voice indeterminate, disrupts and contests contemporary social and moral assumptions in a number of ways: by "unsettling the reader and depriving him of solid points of reference from which to evaluate a character's actions," dissolving "the position from which marriage and adultery—or any similar pair of moral alternatives within existing society—could be genuinely distinguished," and challenging the "ideal of pure art, unsullied by the impurities of life" by "constantly overcoming the distance between the author and his characters." ${ }^{.12}$ In these ways, LaCapra sought to oppose the unsettling and, in his view, ultimately revolutionary implications of Flaubert's "carnivalesque" discursive practices to the author's professed allegiance to "pure art."

Yet for Seigel, LaCapra's reading overlooks what the carnivalesque and pure art share in common: the fact that neither can exist outside an ideal and purely formal realm. Both of Flaubert's aspirations demonstrate that "no ideal [can] be realized in actual life." They serve as "constant reminder[s] that art alone ... remained the sole ground on which the ideal could be pursued." Seigel adds, "To attempt to realize it elsewhere was exactly the romantic temptation Flaubert constantly fought—in himself as in others. ${ }^{{ }^{13}}$ The crucial point for Seigel is that art—a fact that Flaubert's case exemplifies particularly well—arises from life's concerns and

\footnotetext{
11 Dominick LaCapra, Madame Bovary on Trial (Ithaca and London, 1982).

12 Seigel, review of Dominick LaCapra, Madame Bovary on Trial, Journal of Modern History $56 / 1$ (1984), 160-62, at 161.

13 Ibid., 162.
} 
yet assumes formal properties that make it something inherently different from life itself. Because it is able to offer a kind of acute consciousness of the limitations and frustrations we experience in life, the temptation to see art as endowed with the capacity to "change life" will always be powerful. But the inclination of modern criticism to assert that what can be achieved in art can somehow be actualized in life itself is to make the same mistake - though presumably without the tragic consequences - as Emma Bovary, whose fate resulted from her failure to distinguish between literature and ordinary life.

The question of the demarcation between art and life is one that Seigel specifically addressed in an essay from 1996, tellingly entitled "Boundaries." Here, Seigel responded to a position that novelist Joyce Carole Oates had taken on a recent controversy. In the New Yorker, art critic Arlene Croce published an essay explaining why she would not review a dance piece by Bill T. Jones featuring AIDS victims, due to her misgivings about the very idea of "victim art."14 Oates had publicly challenged Croce's decision, wondering why the incorporation of "authentic experience" into a work of art should necessarily place it "beyond criticism." 15 In his essay, Seigel sided with Croce over Oates by invoking the example of Charles Baudelaire, a central figure in Bohemian Paris (and a strategic one in The Private Worlds of Marcel Duchamp). In his art criticism, Seigel explains, Baudelaire had discussed the work of fellow poet and Bohemian Hégésippe Moreau. While Baudelaire could easily identify with the suffering that Moreau, as a denizen of Parisian society's outer reaches, had experienced, he reproached him for equating art with "marginal living and suffering" as such. Moreau's mistake was to confuse life-even in its most tragic and painful moments-with art, and specifically with the kind of transcendence that art is uniquely capable of achieving. Describing Baudelaire's position, Seigel affirms,

Precisely because modern artists had to plumb the depths of society and the self, art could only survive, he thought, if artists developed a renewed consciousness of their commitment to discipline, work, and formal unity. Vision had to be sought in regions artists had shunned before, but woe to those who confused the passivity that drink or drugs or erotic arousal, or even political intoxication, induced, with the aesthetic need to

14 Joyce Carol Oates, "Art and Ethics? The (F)utility of Art," Salmagundi 111 (1996), 75-85. Oates does not actually mention the Bill T. Jones controversy in this essay, though she had in the Times piece referenced below.

15 Joyce Carol Oates, "Confronting Head On the Face of the Afflicted," New York Times, 19 Feb. 1995, at www.nytimes.com/1995/02/19/arts/confronting-head-on-theface-of-the-afflicted.html, accessed 5 Feb. 2017. Oates was responding to Arlene Croce, "Discussing the Undiscussable," New Yorker, 26 Dec. 1994, 54-60. 
struggle to the depths of one's being, in order to give active unity and formal clarity to the poet's images of a higher life. ${ }^{16}$

Yet modern culture is afflicted by a problem that Simmel had intuited: the belief that art can only achieve its transcendent goals by tearing down the borders between art and life and through the creative destruction of form. Thus Rimbaud, in Seigel's telling, believed that "Baudelaire had kept himself from becoming a real visionary by his retrograde and small-minded cult of form, his refusal to identify art with the creative destruction of boundaries." ${ }^{17}$ This trend accelerated in the work of avant-garde figures like Antonin Artaud and especially Georges Bataille, who was motivated by a "persistent cult of what he called the informe." In Artaud's celebration of cruelty, in Bataille's glorification of the most bestial activities as the realization of an aesthetic sublime, "the destruction of form passes over into the abolition of any boundary between art and life." 18

The conception of art that Seigel associates with Baudelaire and (in the earlier piece) Flaubert and that he seeks to defend finds its most coherent expression in Kant's aesthetic philosophy. In his Critique of Judgment, Kant maintains that we derive our idea of beauty from experiencing objects in the natural world that seem endowed with a sense of purpose that human activity alone can confer. Understood in these terms, beautiful art dangles before us the ideal of a world shaped by human purpose rather than material necessity. Seigel explains: "Beautiful objects, Kant held, affect us so much because they give us the sense that purpose, rather than causal necessity, can impart shape to the material world, and works of genius rise above the everyday by virtue of their ability to combine pure freedom with adherence to an internally-generated set of rules." ${ }^{19}$ These rules exist to achieve the formal purity that Baudelaire believed was essential to genuine art. Art that abandons the pursuit of form risks renouncing the very means by which art proffers us that sense of purposiveness and the feeling of freedom it entails; art without form risks being indistinguishable from mere reality, with all its material constraints (this is the problem posed by Duchamp's readymades). But while art can give this unique sense of freedom-the sensation of being released from the material constraints of ordinary existence-it nonetheless demands of us one concession: that we recognize that art is an ideal sphere, an artificial realm that may inspire how we live our lives but which can never be conflated with life itself. This idea of art as form implies that art has qualities that are worth maintaining "precisely because life can never preserve them." As

16 Seigel, “Boundaries: A Response to Joyce Carol Oates," in Salmagundi 111 (1996), 96-104, at 99.

Ibid., 100.

Ibid., 101.

Ibid., 102. 
a cultural critic, Seigel thus admonishes us not to lose sight of the importance and value of form in the face of those seductive forces that-from the avantgarde to activist art, from postmodernism to multiculturalism's exaltation of difference-lure us with "a promise to transform existence so exalted that it levels all else before it." ${ }^{20}$

\section{FORM AS AN ALTERNATIVE MODERNITY}

The tension between form and dissolution that structures much of Seigel's thinking seems to evoke no work in the philosophical tradition as much as Friedrich Nietzsche's first book, The Birth of Tragedy. In that work, Nietzsche (who had an important impact on Simmel) claimed that the state of tension between what he called "Apollonian" and "Dionysian" forces decisively shaped ancient Greek culture and perhaps culture in general. Seigel explains Nietzsche's distinction in this way: "Dionysus, the god of music and revelry, reigned in those moments when the flow of pure natural energy overwhelmed the appearance of stable boundaries between individual objects, fusing together things that seemed to be separate before." Apollo, however, was "the god of light and of the plastic arts," who "presided wherever clarity and stability seemed to reign." Apollo embodied, moreover, the "principium individuationis, the ordinance of nature that made life appear only in individual forms." According to the Apollonian principle, "Individuality was the modality through which existence manifested itself” (IS, 539).

As Seigel frequently acknowledges, it has become something of a truism in cultural and intellectual history that modernity consists of a variety of processes through which traditional forms are dismantled, creating a state of flux-in social relations, cultural norms, and individual identities- that can be alternatively exhilarating and disorienting. Modernity, as conventional wisdom would have it, is Dionysian. A thinker as different from Nietzsche as Marx acknowledged, in his own way, the Dionysian powers that modern social relations unleash with his famous (and often quoted) remark that, henceforth, "All that is solid melts into air, all that is holy is profaned." Seigel himself takes this description of modernity very seriously, and, as we have seen, different versions of it provide the theoretical underpinning of many of his books. Yet Seigel is by no means convinced that modernity's fate is inescapably Dionysian. In his work, the figures he deems most exemplary are modern thinkers and artists who take full measure of the energies released by these Dionysian forces, yet precisely in order to produce cultural forms exhibiting the discipline, virtuosity, and coherence found in earlier periods, even

\footnotetext{
$20 \quad$ Ibid., 104.
} 
as they express the distinctive character of the modern experience. Perhaps it would be going too far to assert that Seigel sees modernity as Apollonian; it does not, however, seem unreasonable to say that his project is to identify and support the Apollonian potential lurking within modern culture.

Grasping the possibilities of formal unity and coherence in modern circumstances requires understanding, in the first place, the character of modern life itself. Seigel seems to broadly accept Hegel's account of modernity that he presents in the opening chapter of Marx's Fate, which draws on his commentary on David Hume's History of England. "Contrasting modern fragmentation with ancient harmony," Hegel maintained that moderns could no longer be the "whole men" that the ancients had once been because their activity was limited to specific domains - in short, because they were subject to the division of labor. Quoting Hegel, Seigel observes, "Modern achievements therefore combined 'the consciousness of the universal and at the same time opposition, particularity." Consequently, in modern times "opposition and particularity did not destroy unity but formed its basis" ( $M F, 26)$.

It was his acute awareness of these conditions and their implication for artistic expression that, in Seigel's judgment, makes Baudelaire the paradigmatic modern poet. Baudelaire understood that art in his century could not "draw people to a higher life by hitching its wagon to the old stars of religious belief, shared values, or universally recognized models of form," as "none of these engines of idealization retained its former power." ${ }^{21}$ Art's vocation was still to offer a "superior kind of existence," but this meant drawing on energies that were located not in a realm transcending daily life but in society's lower depths, where Dionysian opportunities were abundantly available. Baudelaire, Seigel reminds us, "employed a wide variety of agents to draw nurture out of this soil: drink, drugs, sexual arousal, even ... revolutionary politics, all of which were capable of unleashing visions of a life beyond the horrors of the here and now." $22 \mathrm{He}$ realized, however, that the stimulation found in these experiences-notably the transcendent heights attained through the intoxicated "vaporization" of personal identity - was not in itself art. The lesson of Baudelaire, for Seigel, is that only the rigorous use of form can extract an aesthetic essence from these inchoate experiences. Baudelaire understood, in short, that "whatever form of experience art drew on had to be imaginatively reconstructed, distilled and purified by artifice and form." ${ }^{23}$ His poetic works - particularly The Flowers of Evil_-achieved this by articulating such daemonic experiences as intoxication, ennui, "spleen," and the isolation of urban life through graceful alexandrines and exquisitely crafted

\footnotetext{
$21 \quad$ Ibid., 98.

22 Ibid.

23 Ibid., 99 .
} 
quatrains. Thus Baudelaire stands out, in Seigel's pantheon of modern artists and thinkers, for the lucidity with which he grasped the flux of contemporary culture, but above all for the discipline and intelligence he put into creating a formal language and technique that were adequate to modern concerns.

It is this perspective that, in many ways, informs Seigel's well-known skepticism towards postmodernism, particularly as it relates to the self. What characterizes this intellectual trend, for Seigel, is precisely the Dionysian cult of the informe, the "view that all boundaries and limits are forms of oppression and elements in the system of power and control we need to contest." ${ }^{24}$ Yet as his preference for Baudelaire over Hégésippe Moreau indicates, Seigel sees this position as the solution de facilite in the face of the fluidity of modern culture. Seigel's critique is striking in the way that it turns many common assumptions about postmodernism on their head. Whereas the latter is still often viewed as a philosophical position emphasizing plurality over unity, ambiguity over clarity, and the conditioned over the conditioning dimensions of human experience, Seigel seeks to emphasize that, in each of these pairings, the opposite is the case. Consider his understanding of the self compared to postmodernism's. For Seigel, selfhood is an idea that takes root in three dimensions that are inevitably linked yet irreducible to one another: the body, social relations, and reflection. This means that while most human beings seek some kind of integration between these different dimensions - and may be more or less assisted in these efforts by the culture in which they happen to live-such efforts will always be, to some degree, partial, provisional, and imperfect. Personal integration, to the extent that it is achieved, is likely to entail some remainder, some supplement that finds no place in the integrated whole. Seigel writes, "If the self takes shape at the intersection of multiple coordinates, each with a different vector, then it is bound to be subject to competing pressures and tensions. The demands of the body strain against the limits culture imposes on need or desire, while reflectivity may set itself against both relational and material modes of self-existence" (IS, 7). The idea of "pure, homogeneous selfhood" or a "seamless existence" becomes possible only when the self is posited along a single dimension (IS, 8). Seigel's complaint against postmodernism is that it does precisely this: Nietzsche and Heidegger, Foucault and Derrida have typically identified the self with one of these three dimensions (though they vary in which one they emphasize).

Seigel observes, furthermore, that one-dimensional accounts of selfhood are prone to a schizophrenic tendency that lurches back and forth between viewing the self as hopelessly constrained and picturing it as utterly unbounded. These accounts are striking in their "absence of ambiguity" $(I S, 9)$ : rather than placing

\footnotetext{
$24 \quad$ Ibid., 103.
} 
the self somewhere in the middle of the spectrum of constraint and freedom, these accounts are committed to an all-or-nothing outlook, an alternative between "noself and all-self" $(I S, 10)$. What interests Seigel in particular about the discussion of the self in seventeenth- and eighteenth-century Britain is that thinkers like Locke, Mandeville, Hume, and Smith believed that the self was heterogeneous, abstruse, and by no means fully autonomous - yet still believed personal integration was an achievable and meaningful goal. None of them, he writes, regarded "the self as fully integrated, homogeneous, or without tensions and fissures; each saw the persistence of rifts and strains in selfhood as unavoidable, and as an incitement to the continuing project of personal integration" (IS, 167).

Thus selfhood, for Seigel, is a kind of form, one that is constructed from the diverse coordinates that shape human life. Recognizing this fact does not mean adhering to a notion of the self as seamless, but it does involve acknowledging that what we frequently mean by selfhood is an aspiration to achieve personal unity and coherence on the basis of the multiple elements the self has to work with. Seigel explains, "To acknowledge [the] strains and stresses [between the self's different dimensions] is not the same as to deny that individuals can attain a measure of stable unity and integrity ... one can give close attention to them while still regarding some significant degree of consistency and self-directedness as a goal worth pursuing" (IS, 7-8).

The notion that form can be squeezed from the flux of modern life is, ultimately, the reason for Seigel's belief that we must take the opportunities afforded by bourgeois life seriously. This position has, needless to say, put him at odds with many a scholar for whom the critique of the bourgeoisie-not to mention capitalism-remains the unsurpassable horizon of social and political commentary. Significantly, the term Seigel proposes as an alternative to the notion of the bourgeoisie as a social class is that of bourgeois existence as a "form of life." What interests him about bourgeois life is not-at least not primarily-the creativity or productivity of capitalism, its technological inventiveness and its entrepreneurial feats; it is not the opportunities it enables, or even (simply) the freedom that it makes possible. Seigel's attention to the value of bourgeois life is not a cheer for capitalism (though it not exactly a jeer, either). The grounds upon which Seigel defends bourgeois life are, rather, Apollonian. The form of life associated with the European bourgeoisie provides a framework for shaping and thus living life that recognizes with little nostalgia the obsolescence of traditional (ascriptive, teleocratic) forms of life without allowing itself to sink into the void of life-without-form. This is why he believes that Bohemia is best understood as not so much the antithesis of bourgeois life as a possible variant of it. It is one, though not the only, "force operating against the assumption that bourgeois social relations can create new possibilities only by preparing their own destruction ... if its history has anything to teach us, it is that individuals in modern society 
can explore forms of action and experience, enter new territories of personal and social life, without the cataclysm of revolution" $(B P, 394-5)$. The dissolution not only of traditional frameworks, but also even of those associated with earlier forms of bourgeois society, must, for Seigel, be assessed in terms of the kind of life they make possible. He writes, "what fuels the accelerating speed with which even newly created practices and expectations are left behind or cast aside is not any overall weakening in the structures within which individuals and groups act-markets, states, webs of communication-but on the contrary their increasing strength and power" $(M B L, 526)$. More than anything, bourgeois life is unique in the way that it structures human life not around ends (i.e. a telos), but around means, thus "opening up opportunities to pursue individual goals and aims for which only various kinds of inherited assets provided sufficient support before" ( $M B L, 526)$. Not capitalism's creative destruction or the market's irrational exuberance, but the Apollonian promise of form amidst fluidity, is the normative basis of Seigel's apology for the value of bourgeois life.

\section{CONCLUSION}

Seigel's commitment to the idea of form is evidence of the way in which his work goes beyond that of a historian — as great as his contributions to the field of history are-and extends into the realm of social and cultural criticism. This essay has considered three meanings of the idea of form in Seigel's work: the position that individuals over the course of their lives strive for personal integration and coherence in a way that can, particularly in the case of significant cultural figures, be reconstructed by intellectual historians; the claim that art and other forms of cultural expression arise from existential concerns yet aspire to a "formal unity" that is jeopardized by attempts to reintegrate form into life itself; and the insight that despite the fluidity and formlessness entailed by the social transformations known as modernity, the quest for form (including in the two senses mentioned previously) nonetheless remains essential to modern life, as an expansive view of the significance of the bourgeois "form of life" attests.

Though Seigel's vast learning provides considerable evidence in support of these positions, his work's importance goes beyond its historical contribution: it should be read as a theoretical exploration of the anthropological claim that human life is characterized to a significant degree by its capacity for and cultivation of form. This very position may be one reason why Seigel's work frequently seems "untimely": among academics as well as in contemporary culture more broadly, formlessness still has a seductive allure, thanks to which which it maintains its position at the vanguard of much contemporary thoughtwitness the continuing appeal of such concepts as difference, hybridity, the 
sublime, performativity, jouissance, the "real," and the "event." The fact that Seigel continually addresses these ideas (or, more precisely, their deeper cultural roots) and recognizes them as temptations that are constitutive of modernity testifies to the openness and liberality of his thought. Yet what we owe him as a thinker and as a cultural critic is the way he seeks to orient us towards a different way of thinking, in which the fluidity of modern conditions may be the starting point but not the end of our exploring. Amidst Dionysian flux, Seigel teaches us, Apollonian form remains possible-and perhaps even necessary. 